\title{
Documentation of Platography workshop (Plate Lithography) at the Lalit Kala Academi
}

\author{
Piyali Paul* \\ *PhD Scholar, Graphic Department, Visva Bharathi University \\ Workshop venue - Lalit Kala Academy, Lucknow, India. \\ Workshop Date $-18^{\text {th }}$ of November $2016-24^{\text {th }}$ of November 2016. \\ Residence of the artist - Ramen kastha. (Contemporary practising printmaker)
}

First Author- Ms. Piyali Paul, Qualifications, Visva Bharati University and silverlineofcloud@gmail.com. Second Author- Name, Qualifications, associate institute and email address

\begin{abstract}
Platography is a modern technique of printmaking in India nowadays. However, western artists such as Albert Durer used this technique as an artistic medium from the nineteenth century. Platography is an alternative way of Lithography. However, artists are getting more attraction towards Platography than Lithography due to a shortage of resources like Limestone. Many schools and colleges are trying to adapt Platography practice due to various printmaking procedures, and as experimental processes, different organizations, studios, and collaborative studios are promoting new techniques of printmaking.
\end{abstract}

Index Term- Platography, Plate Lithography, Printmaking, Planography,

\section{Introduction}

Platography is a process where mechanically plates are grained by thousands of metal balls rotated circularly beneath the aluminium plate. Then drawing is made within the aluminium plate with the help of grease-based ink. Afterwards few steps are followed to complete a plate lithography process, which is described below. The mechanically grained aluminium plate has been used as printing surfaces since the earliest periods of lithography. There is a connection between lithography and Platography. Lithography was first discovered in 1798, but the use of zinc was firstly revealed by Alois Senefelder as early as 1818 (Antreasian, Antreasian, Adams, Staff, \& Workshop, 1971). After that, many lithographers from European regions, such as England, France and Germany, shortly described usage of zinc plate in their studies. Soon after, another metal called aluminium was introduced to the printing trade in 1891(Antreasian et al., 1971). However, there is significantly less evidence that is noted and published online regarding the usage of these metals in the field of visual art. Hence, future studies regarding the use of these metals in the artistic area need to be evaluated, and it may hoard more evidence in the coming future.

A workshop is a period of discussion and practical work on a particular subject. A group of people share their knowledge and experiences regarding building up and repairing things with different tools and experiences. The educational program is designed to monitor participants' practical skills, techniques and ideas in a workshop, which participants can use in their work and bear it as a lifetime experience. Workshops are often designed for participants who are working together or working in the same field. Here in Lalit Kala Academi, in Lucknow, several workshops are organized by a government body named "Ministry of Culture". One workshop was held on the 'Platography' technique within the different workshops, rarely practiced in day-to-day work. Participants who are actively bothering in this rare workshop may get more influence and an audio-visual experience to remember throughout their lives. Such workshops are held not only for one day but also for weeks with fixed numbers of participants throughout different sessions. However, many workshops may end up with many doubts and suggestions for further study for those interested in continuing this practice in the future. Especially for those working together, a workshop can help them dissect their doubts and initiate a sense of maturity regarding the particular work and create good bonding.

In numerous documented studies, Dr Nirmalendu Das had said that sometimes 'Platography' was mistakenly mentioned as 'Plate Lithography' (Prof. Kashinath Salve, 2016). The term "Plate lithograph" was adapted paradoxically from Greek words, such as "Litho" (etymologically "Litho" the word had been derived from the 
Greek word "Lithos" meaning stone) and "Graph" which had been derived from the Greek word "Graphic" meaning writing or drawing and the procedure of Lithography was first invented by Sir Alois Senefelder in 1796 (Philip B.Meggs, 2012). Here, plates were of different forms, such as stone plate and metal plate. Actually, both stone and metal plate surfaces were used for the particular process called "Planographic printing", in which printings were adapted from any smoothed surface. In this method creating an impression with the help of stone, characters were much popular and widely used. On account of this, the term "Plate Lithography" came into notice and distinguished the use of metal plates from stones, which is, however, technically wrong in our current practice. But due to its over popularity, the term still trends to be in current practices both academically and practically. Besides, this acceptance perhaps is since lithography is historically valued more than printing from metal surfaces. However, this error needs to be corrected. Hence, I coined the term from "Plate lithography" to "Platography", in which "Platography" means any printing was made from a smoothed metal surface. Gradually, the term "Platography" gained more acceptance and is still gaining in the main field of academics. Platography is a medium that has been explored and developed in recent years as an alternate technique to lithography. In lithography, the stone's surface remains plane; thereby, the more accurate label for this method is 'Planography'. New materials, such as thin metal plate (made up of aluminium), replaced the Limestone in current practice. However, many printmakers prefer to work on litho slabs. But unfortunately, this stone is not excavated any more. Platography workshop was a national level workshop, so the regional Centre invited ten selected students from different art colleges in India. These colleges are Aligarh University, Jamia Islamia, Baroda, Rajasthan university, Khairagarh University, B.H.U university, Lucknow regional Centre and a few more. This workshop was held to learn and demonstrate new techniques of Platography processes so that printing gets more value in the coming future. Platography practising was a new printmaking technique, and this technique was less prevalent among students than other techniques, such as woodcut, engraving, intaglio, stone lithography. Therefore, learning and practising Platography was the primary motivation of this workshop.

\section{Workshop venue and participants' description}

The Lalit Kala Academy, which resided in Lucknow, gave this opportunity and placement for new young printmakers to build better knowledge and establish self-esteem. This motivation gave us an opportunity for effective collaboration with student and artist from different corners of the world and helped us to build our experience with individual and group discussion. This workshop was only the starting point of a journey and their regular intervals to adapt them to the changes happening in every moment of our life. Ten participants learnt, practiced and presented 10 Platography prints during that workshop.

This collaborative workshop process was an essential aspect of this paper and produced printmaking artwork, compelling evidence of Platography, which I was discussing here. This paper was meant to be presented as an example of the whole processes of Platography printmaking technique, utilization of studio space, developing collaborative working field among the students and artists and understanding of the artist profiles with explaining regarding the fabricating printmaking process. One of the residence artists named Ramen Kastha delivered a niceties demonstration of the advancement of Platography medium as printmaking process at the studio of Lalit Kala Academy, in Lucknow.

\section{Description of the Platography}

Platography is a planography process. Romen Kastha gave some demonstrations regarding the Platography process using alumunium plate. So, it's called "aluminium plate lithography". In almost every printmaking workshops and educational establishments to develop planography technique replaces the Limestone with the aluminium plate. Mainly ball-grain aluminium plates are being used for this planography printing process. Aluminium plates are seen as an attractive alternative rather than working on stone. Mr. Kastha demonstrated how to prepare an aluminium grain plate manually for this technique instead of a ball-grain machine. He also disclosed the process of utilizing the old used aluminium plate for new print working ground.

\section{Characteristics of Aluminium Plate}

For preparing lithography, grain surface commonly used carborundum powder similarly for achieving aluminium plate fine-grain surface used thousands of ball bearing. The necessary graining of the aluminium surface is done mechanically, either by sand-blasting or by ball graining. Nowadays, most of the printing plates are grained in an electrolytic process called anodizing, an electrochemical graining process with subsequent oxidation (Hudymma, 1991). In this workshop, readymade plates had used. The plates rinsed and dried, and each then checked to ensure that the surface is uniform and level. It is common practice for alumunium to be used only once for a single image, although the plate may be counter etched a number of times during drawing and processing. The processing of alumunium plates closely resembles the stone, although phosphoric and tannic acid etches used instead of nitric 
acid. The alumunium plates came with few problems during etching, like working with new plates, the etched area remains invisible, and there is a maximum chance to catch excess ink or scam for used containers. In this experiment, the image printed from alumunium more sharply defined than the printed from zinc and more closely resembles images printed from stone, for this whole process of printing using a direct flatbed press. Being even more lightweight than zinc, large scale plates are more easily handled, and potentially colossal print is possible.

\section{Preparing technique of the alumunium plates}

- At first, the artist used ball grained plates as a medium; it was relatively easy to cut a plate to whatever size required and generally, he found that half and quarter plates were suitable for work.

- The size of the negative image should be similar to the plate size, and the required print paper dimension should be larger than the plate.

- Newly grained alumunium plates were highly sensitive to both grease and moisture. Great care should be taken when handling them. The plates were a store, wrap up in a dry environment.

- More he said, alumunium is highly prone to oxidization. When exposed to the air, particularly when it is humid, although this is not normally a problem, oxidization can sometimes appear as a rash of sports during printing that can be difficult or sometimes impossible to remove. That's why the plate should be protected with silicate solution coating during plate preparation, which can be available from the supplier also.

\section{Washing the plate}

Before drawing on the plate, the artist sensitized it either by washing it with hot water or applying an appropriate counter etch solution. Non-availability of grinding machine in the Lalit Kala Academy, Lucknow, Mr. Ramenn Kastha carried ground expose plate from Calcutta. At first, he removed the image by nova delete and desensitized it. Then wash it with hot water and applied an appropriate counter etch. Now the plate is ready for image-making.

\section{Drawing on Alumunium Plate}

After sensitizing the plate, it is advisable to draw on to it as soon as possible. So, at first, he had drawn details of composition to the surface of the plate using Conte, glass marker and used $\mathrm{x}$-toner. Also, after using toner, he heated the plate to fix the drawing. Aluminium plate is susceptible to grease. Therefore it is essential that excessive application of grease is avoided. Instead of using grease medium, the application of toner is more valuable. Though toner is a dust medium, it is a little challenging to create the image with it. Otherwise, for using traditional materials such as crayon and Tuche (greasy medium), it is advisable to limit the layering of this medium. Tusche should always be well prepared in advance. Gum Arabica desensitizing agent can be used as a mask or stop out the solution to protect the negative areas. When working in this manner, he applied the gum stop-outs first and ensured that it dried before continuing with the drawing. He guided me to learn using "deletion" need to be carried out carefully to avoid damaging the granular structure of the plate. Normally chemical deletion is the preferred method. So, 'Nova Delete' (chemical) used to erase the image.

\section{Etching Alumunium Plate}

Once the image has been drawn on the plate, it was then processed so that the drawing materials can be removed, replaced with ink and for some reasons, it occurs on stone, although a different chemical and different producer are used to etch. Unlike stone lithography, however, etching causes the formation of oleo-magnate of lime within the structure of the stone; this cannot occur on aluminium; obviously, the plate is a different chemical structure and lacks the porosity found in Limestone.

\section{Formulating etches for alumunium plate}

The reaction between nitric acid and alumunium resulting oxidization and eventually create corrosion on the plate surface, and for this reason, etches are formulating. Then he used a mixer of Gum Arabic, Phosphoric Acid and tannic powder, which called 'Tapem' for plate etching. The artist said the use of 'Tapem' must be limited; it shouldn't stronger than PH1.5 otherwise, the plate will be affected if Tannic acid is unavailable for making 'Tapem', a substitute prepared with gum Arabic and phosphoric acid. 
Table 1: List of materials enlisted by Mr. Ramen Kastha himself for Aluminium plate Lithography.

\begin{tabular}{l|c|c|c}
\hline & Light & Medium & Heavy \\
\hline $\begin{array}{l}\text { Rubbing hard crayon } \\
\text { copal }\end{array}$ & Gum & $1 / 4$ & $50: 50$ \\
\hline Rubbing crayon medium & $1 / 4$ & $1 / 3$ & $2 / 3$ \\
\hline Rubbing crayon soft & $1 / 3$ & $50: 50$ & TAPEM \\
\hline Liquid drawing ink & $\begin{array}{c}\text { Gum } \\
\text { Soft etch }\end{array}$ & $\begin{array}{c}\text { Gum } \\
\text { Soft etch }\end{array}$ \\
\hline
\end{tabular}

\section{Different type of formulated etches}

a) $1 / 4$ Tapem etch - is mixed by adding $15 \mathrm{ml}$ gum Arabic to $15 \mathrm{ml}$ of 50:50

b) $1 / 3$ Tapem etch - is mixed by adding $20 \mathrm{ml}$ gum Arabic to $10 \mathrm{ml}$ of Tapem

c) $2 / 3$ Tapem etch - is mixed by adding $10 \mathrm{ml}$ gum Arabic to $20 \mathrm{ml}$ of Tapem

\section{Procedure for completing the first etch}

Successful etching of plates, like the etching of stone, is mainly dependent upon good preparation, skill and experience, all of which can be developed through continuous practice.

A particular area where reserved for rolling ink, and a level bench area was placed for stone support can be used to hold the plate in position.

For etching the plate, have ready the following materials and equipment:

- A Bowl of cold, clean water

- A small gum sponge that has trimmed to remove sharp edges

- French chalk and a large soft household paintbrush

- Two pieces of soft cheesecloth or fine muslin gathered up into balls

- A soft Japanese brush used only for etching purpose

- Tapem

\section{Process of preparing the Platography plate according to the artist (Mr. Ramen Kastha)}

a. Set the plate on a flat level surface.

b. Using a large soft brush, apply is covered. The chalk helps to avoid smudging of the drawing materials. Allow the gum etches to act directly on the plate surface.

c. The etching process was consistently applied, starting with the weakest etch first and finishing with the strongest. Tapem used to get the final etching effect.

d. After completing the first etch, the plate then needs to be processed, which involves removing the existing image that has been drawn with crayon and tusche and replacing this with ink.

e. Then the image washed out with pure turpentine with clean, soft cotton. Allow the grease drawing to dissolve slowly, and avoid rubbing the surface of the plate in an unduly abrasive manner. 
f. Use clean cotton or rag to clean the plate further using acetone. This removes all traces of grease from the container and provides a good clean surface for the lacquer.

g. Apply lacquer on the plate and, using a clean, soft rag, spread this evenly across the whole of the image.

h. Another clean rag used to buff the lacquer all part of the image.

i. After heated the plate

j. Then applied asphaltum to wash the plate

k. After dumping, the plate rolled with black ink.

1. Then the image was automatically come out.

$\mathrm{m}$. Then set the paper on the plate.

n. Then artist got his print.

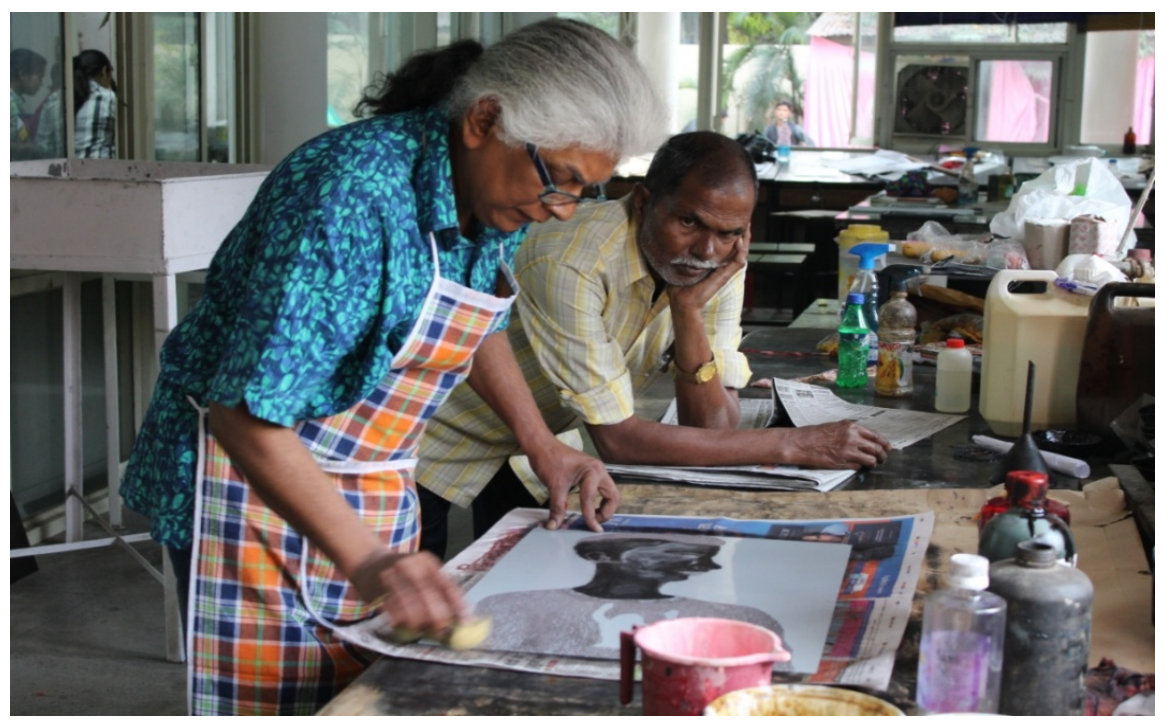

Figure 1: Showing process of Platography by artist Mr. Ramen Kastha.

\section{Conclusion}

To conclude, all the evidence has been collected from the Lalit Kala Academy at Lucknow. That evidence is videos, images and recorded interview of the artist (Ramen Kastha) and that evidence are very important for this paper to validate. Moreover, supporting evidence could be granted proof that Platography practice is still successfully going in each corner of the world as an extraordinary artistic practice. However, the technique of Platography I am working on is very new and has excellent outcome but has limited access to all students due to lack of knowledge and professional expertise. Besides, Platography is a new approach of artistic practice in printmaking medium that involves new audiences and helps them get nourished with a unique experience. Hence, I hope this work might help evaluate the Platography technique and provide more evidence regarding it in current literature.

One core issue discussed during the session, how planography has artistic and aesthetic value in contemporary printmaking practice. I am explaining these are the best understood by considering the categories of function, process, and materials and organized a write-up to provide a set of reading information practice in this paper. In this paper, I explain the categories and functions of the Platography process with my best understanding gained throughout this productive workshop. This reading information can be beneficial for those interested in working in the Platography medium as an artist or as a student. 


\section{REFERENCE:}

Antreasian, G. Z., Antreasian, G. Z., Adams, C., Staff, T. L. W., \& Workshop, T. L. (1971). The Tamarind Book of Lithography: Art $\&$ \& Techniques. Tamarind Lithography Workshop. Retrieved from https://books.google.co.in/books?id=9xhYAAAAMAAJ

Hudyma, M. W. K. ; S. B. ; E. (1991). Electrochemical Impedance Analysis of the Wear of Planographic Plates. Corrison, 47.

Philip B.Meggs, A. W. P. (2012). Meggs' History of Graphic Design (5th Editio).

Prof. Kashinath Salve. (2016). 111 Platographic expressions (1st ed.). Ahmedabad. 


\section{AUTHOR}

First Author - Ms. Piyali Paul, PhD. Scholar, Visva Bharati University, Santiniketan. Emailsilverlineofcloud@gmail.com. 